And lastly, there is the case of the general practitioner or family doctor, who is certainly not least worthy of consideration in any post-graduate scheme of education, especiaily when we remember that he is not only the back-bone of the profession but that he forms by far and away the majority of its members. No doubt the courses referred to in the last paragraph meet his wants, but to attend them means as a rule, on account of the time and expense involved, the foregoing of his much-needed annual holiday. Hence it is an experience which cannot be often repeated.

One cannot admire too much the doctor who sacrifices his holiday for the purpose of making himself more useful to the community and it is in the easing of the burden of this altruistic urge that we see the virtue of the special intensive week-end courses about to be inaugurated, and for which we are sure there is a great future. They have the advantage that the time consumed is not more than even the most busy practitioner can occasionally spare, the time is fully and beneficially employed and the survey embraces all branches of his work so that variety will lessen the strain involved. To us one particularly fortunate arrangement seems to be that all the members attending the course will during its progress live together so that they will obtain that most valuable stimulus which comes from mutual discussion of the day's work.

\title{
ERRATA.
}

We regret that through an oversight in the proof-reading, the following appeared on page 286 of the August number of the Journal (9th line from the bottom of the page) " Refusal of a fotus to remain as a breech often implies a contracted pelvis".

The author has requested us to correct this.

For the word "breech" read "vertex".

\section{To the Editor,}

Sir.-I would be grateful if you would allow me space to correct an error in my Lecture on "Albuminuria and Eclampsia" which you published in the August number. In the last paragraph the name of Professor Stroganoff appears as "Studgaroff" and I regret that this escaped my notice during the revision of the proofs.

Since the publication, I have received a letter from Dr. Perott, of South Kensington, telling me that his former master, Professor Stroganoff has been publicly disgraced in Russia and sent to exile. I am sure the news of this tragedy will be received with the greatest sorrow by all readers of this Journal.

It is said that prophets have no honour in their own country, and I cannot help thinking that Professor Stroganoff does not lose much, for, outside Russia, he is honoured and revered by Obstetric Surgeons throughout the world.

Yours faithfully,

ANDrew McAllister. 